\title{
Influence of Categories of Modernity in the Consciousness of Young People
}

\author{
Manol Manolov \\ Department of Psychology, “St. Cyril and St. Methodius”, University of Veliko Tarnovo, Veliko Tarnovo, Bulgaria \\ Email: manolov.manolov@gmail.com
}

How to cite this paper: Manolov, M. (2019). Influence of Categories of Modernity in the Consciousness of Young People. Psychology, 10, 1077-1094.

https://doi.org/10.4236/psych.2019.108070

Received: May 21, 2019

Accepted: June 25, 2019

Published: June 28, 2019

Copyright (c) 2019 by author(s) and Scientific Research Publishing Inc. This work is licensed under the Creative Commons Attribution International License (CC BY 4.0).

http://creativecommons.org/licenses/by/4.0/

\begin{abstract}
Definitions such as "liquefied reality", "multiphrenia" and "Proteus personality" are used to describe the new time, postmodernity and personality formulated in the context of this influence. The messages that society directs to describe the "world" of young people are directed at the loss of values, disregard for authority, irresponsibility. It is assumed that the leading cause of these descriptions is the influence of the very dynamic time, the permanent "keeping in touch with database" that leads to the formation of a conflict between the different generations, which is led by the lack of understanding, of continuity. This assumption is also the leading reason for conducting the study among young people. The main objective is to attempt to outline the perception of the categories of the new age-to shade the contents of their consciousness. The age of the respondents, apart from being in the zeitgeist, is also selected in connection with the process of forming identity. It is precisely the way in which reality is adopted and represents the field that meets the experience that will make the person in the future stable. This report presents the part of the research, which lists the closest two associations in relation to the contemporary categories. The results show to a great extent, the increasingly prevalent objectification, understanding and interpretation of reality through direct messages and the decreasing refraction of the reality through the metaphor. The results lead to the claim of available knowledge, but lacking awareness, breaking the reality through individuality. This is why it is sought both in the information flow and in relation to the intergenerational distance available and the neglect of the experience compensated by obtaining the available information.
\end{abstract}

\section{Keywords}

Postmodernism, Consciousness, Hypermodernity, Categories of Modernity, Attitudes 


\section{Theoretical Frame}

The Living as a process is a function of the dynamic and complex intertwining of social factors in the context of the individual components in the plastic structure of consciousness, which sets the simple and random events with strictly individual meanings. "Movement" from outside to inside to the subjective, its remodeling and its returning to the "outside", makes sense of the social, which is the driving force of the individual's pursuit of belonging, verifying reality and unification. The transcendence of individuality and the exchange of one's own reality with that of the others is possible through communication. In turn, and in the modern times, there are various channels. These channels allow the intertwining of reality except in superficial categories, and also in relation to social determinants such as culture, nationality, language, religion, politics, and so on. Global processes and intertwined social differences lead to the emphasis on freedom of personality, ways of expression and individual differences. For them, new categories are created, which, although they define the social reality, are also associated with a different attitude towards them. This different attitude is most closely associated with transgenerational communication, which can be considered as a direct form of communication and the origin of the image of the reality that is formed in relation to the identity process, respectively relevant to creating attitudes towards the different social phenomena. "As a process, identity guides and controls the resources that a person has. This process also includes social influences on personal choice, as well as choices from the broad social context—friends, family, environment, work, politics" (Bakracheva, 2009).

That work has attempted to examine both the attitude towards some modern categories and the way they are perceived by the respondents. In particular, the way this part of reality is "personalized" and transforms into part of the identity, part of the living.

Before looking at the results, however, some of the influences of the modern day on the functioning of the personality need to be presented.

The development of subjective reality can be traced back to philosophers. Beginning with Kant, claiming that nothing is observable in its essence, but only with its manifestations, continuing with Schopenhauer, who defines as the only observable essence of his own consciousness and locking himself with Nietzsche, who defines God as dead. It is obvious that social and its influence, explanatory models of science and industrial progress lead to an increasingly intense social influence, which is also the regulator of the individual. George Zimmel defines "the deepest problems of modern life in the individual's aspiration to preserve his independence and the uniqueness of his existence from the supremacy of society, of the historically inherited, of the external culture and technique of life..." (Zimmel, 2014). The intense progress of social, as well as its development, the ever-emphasized alterity, "driving society toward a post-modern self-consciousness through a process of social saturation. The 'traditional' family is being transformed into a process of 'microwave relationships' that are based on individual 
technological needs of each family member. The home is less a nesting place than a pit stops" (Gergen, 1991). "Beyond the effects on the family unit, each individual of this new high-tech age is becoming both overwhelmed and confused with their own personal identity because of the almost limitless impulses made available to them by new technologies. The technologies of social saturation expose us to an enormous range of persons, new forms of relationships, unique circumstances and opportunities, and special intensities of feeling... From this overexposure Gergen argues that we become susceptible to multiphrenia: a splitting of the individual into a multiplicity of self-investments which is partly the outcome of self-population and partly a result of the populated seifs effort to exploit new technological potentials of relationship. He argues that this continued advancement toward an over-populated self will necessarily lead to a condition where the entire idea of a 'rational choice' will become meaningless because of the over exposure in all human lives" (Gergen, 1991). Kenneth Gergen continues with his analysis of modernity, adding that the concept of identity as complete and limited is untenable. Gergen points to three main reasons that lead to the impossibility of a collective, based on the form of a certain value system, Ego continue to exist. These are the increasing mobility of the population, the wide-ranging relationships that support individuals, and last but not least, the strong links that have once been identified as a sense of self have eroded because of a wide range of superficial commitments. Gergen claims that heterogeneous truths, as well as the loss of faith, make people more and more engaged, more subdued and, in this sense, more cynical. One of these reasons he finds in technology. "The technological context works directly to undermine the intelligibility of the traditional self" (Gergen, 2000). The many participants in modern communication, as well as the constant and intense cultural changes, the dynamics of the overpersonal lead to counterproductivity in different aspects of human functioning. Here are included the different types of therapies that require that "talking heals". Interactions change, and cultural influences become increasingly meaningless (Gergen, 2012).

The above also leads to the scars that distinguish the postmodernity of "uncertainty, fragmentation, decanization, lack of self-worth and depth, unimaginability, irony, hybridization... Among the most prominent features of postmodernity, Gitlin highlights: inconsistency, collapses, originals and preferred copies; the enjoyment of the game of the surface, the dissolution of the individual and the reality in various simulations, texts, conversations..." (Sapundzhieva, 2015). Bowman defines life in fragments as detrimental to the moral self. "The moral subject does not survive and finds its place outside the fragment and episode of the particular problem. His actions are orientated by different approaches to dealing with the current task and his duties are related to partial interests. This unloads him from any overall responsibility 'for the Other or for the World' and makes it a foreigner (Sapundzhieva, 2015)".

The constant progress of modernity, however, leads to the development of personality and societies in new "forms" that emphasize certain characteristics. 
In this sense, the definition of hypermodernity also arises. It is associated with consumption and the pursuit of "a better life for themselves and their relatives". These times are associated with "the birth of a new modernity that coincides with the 'civilization of desire'... Hyperconsumption conquers social life more and more, but it functions and follows the hedonistic logic of individual goals and pleasure. In this sense, it is not naive to think that society will thus be homogenized, subject to the unifying consumerist role" (Sapundzhieva, 2018). Hyperparadoxical individualism, which follows the postmodernity inherited from paradoxality - to stimulate autonomy and, at the same time, to increase dependence. A striking example of this is nutrition-after social and religious obligations, responsible individual behaviors-healthy eating, weight monitoring, sports, and so on (Sapundzhieva, 2018) begin to work. In the hypermodern time the attitude towards life changes. "Paradoxes raise anxiety, give rise to fears of rejection by others, aspirations for desired belonging, not by others, aspirations for desirable affiliation, direction of expression in the direction of not rising above others, but not below others" (Sapundzhieva, 2018). The notion of "paradoxical happiness", which is associated with the quest to give a tangible, albeit superficial, answer to the question, "Who am I?" Is already met. The consumption and behavior that follows from it not only builds up part of the identity but can also be seen as a socially desirable goal. "In this sense, financial hardship and personal failures are experienced not only as material, but also as an incompetence, lust, lack of a life perspective...” (Sapundzhieva, 2018). The person is permanently connected to others, they form a network that is likely even when objectively missing the likelihood of physical contact. The social network can be economic, social, personal. The individual is surrounded by relationships-virtual and real. Time for independence is almost impossible. Time with oneself, reflection and self-determination against the background of individual experience is impossible, as it is shared in one form or another, and the opinion, the "verdict" of the others with whom the person is connected is an evaluation and a regulator of reality. "Researchers define hypermodern society as being horizontally, because the world is reduced to screen and is completely oiled" (Sapundzhieva, 2018). The main thesis is that hypermodernity does not mean disappearing or deleting values. There is a new social appreciation, based on personal tastes and individual contradictions. There is a new "global ethical attitude" (Sapundzhieva, 2018). "Hedonism and freedom of choice have become the drivers of this new emancipation. And with the end of the great utopias, that individualism has reached unprecedented dimension... Now, it is the narcissistic pleasure of feeling being differentiated, in relation to the crowd but, without it being tied to the need for recognition: the satisfaction it gives of itself to oneself... He lives a narcissistic individualism: overlapping what is private over what is public and individual well-being over social well-being. In this process, there is a disruption with the rigidity of the disciplinary totalizing perspectives of the pre-modern and modern postures, to establish the full right of the individual, free from those beacons, to enjoy life without restrictions or barriers... To be 
happy nowadays, we have to deal with the ideals (slimness, beauty, speed), we have to deal with what society wishes. It is difficult to be happy nowadays, in a society that is constantly encouraging us to desire, those things, which by definition, we cannot have, in other words, everything" (Laskoski et al., 2013).

The considered intense transition in terms of social functioning places a distance between the different categories of people who have acquired their identity in different time contexts. Undoubtedly, the substrate of the peculiarities of time is the individual who presents it. Also, the dynamics and intensity of development in the field of technology, mobility, sociality, contact cannot be denied. Their function is the intertwining of transgenerational, trans-border, trans-cultural, trans-lingual, trans-social. The pursuit of difference, the lack of belonging to the misunderstood (formed as a value system) and the same is proprietary. It becomes a leader in the formation of identity, and originality becomes a quest that follows from the denial of the liquefied, entangled and virtual reality. "All these technologies essentially contribute to creating, sustaining, or subverting forms of understanding or belief. In today's world the circulation of meaning-in volume, speed, and number of participants-approaches staggering proportions. In the time required to read this sentence aloud, 80 million email messages will have been launched into the world. In the last year (2012) alone it is estimated that 8 trillion text messages were sent via cell phones. Everywhere in motion are meanings being shaped and reshaped on virtually every issue of importance to our lives-government, education, religion, family, work, leisure, the economy, love, appearance, and so on" (Gergen, 2012). Thus, the individual who is closest to the time is also a prominent bearer of modern times. This type of reality is a condition for the social survival of the personality. It has been condemned to process reality in the only current way without being known without the experience of the alternative reality. This leads to the alienation of the individual from the others who are the bearers of the different, past experiences. This is where the author's interest in the study of the internal conflict arises-between what "teachers"-bearers of more than one reality represent what they themselves meet as a condition of existence which is different from what is presented. Account is taken of the fact that the defense mechanisms are stronger than the internal conflict, which also leads to the individual way in which the attitude towards what constitutes a "condition" is formed and is diametrically different from the other, which is a "non-existent alternative". New values are being formed that are relevant to modern times and are different from the values they associate with the traditional, those in which the other generations function. It is assumed that the defensive mechanism resulting from this internal conflict is the negation - the negation of the traditional, the denial of what leads to the form of equality as a condition of limited trans-interaction. On the contrary, this is replaced by belonging to different social categories that are determinant of identity and are a function of individualism. At the same time, it is assumed that the pursuit of originality leads to the denial of the other categories to which the individual does not belong. There is knowledge that is accessible at any moment in 
the information flow, but not awareness, which leads to the presence of behaviors, but not to a deep, internal meaning-emphasizes rational and conceptual. There are three foundations-the denial of the traditional (marriage, family), belonging to different value structures (social categories, inconsistent with linguistic, cultural, national affiliation), emphasizing knowledge and behavior towards awareness and understanding. They should also be descriptive of the reflection of reality in young people. This is also the reason why the choice of the study should be directed precisely in the presentation of their perception, understanding and processing of reality.

\section{Research Design}

The study aims to examine the way in which people aged between 20 and 25 perceive the modern categories Gender, Violence, Social Networks, Tattoos, Vegan, Ideal Body, Addiction, Food, Love, Voting, Marriage, Freedom, Beauty, Fear. They are selected by top 3 experts, subject to $2 / 3$ consistency. Two experts are psychologists-social and developmental, the third is a philologist. The aim is to cover the relevance of the concepts concerned to age, influence in the group and linguistic adequacy. Apart from categories that receive social attention, they also represent phenomena related to traditional values, phenomena, attitudes to which they are associated, and the process of identity. The leading hypothesis is related to the aforementioned phenomena of the present and the basics mentioned above, namely, it is assumed that the persons will objectify the concepts, reducing them to their description. A relevant hypothesis is that the surveyed will define as categories of values that are relevant to the consumer, hypermodern society. It is assumed that respondents will appreciate more basic needs than symbolic and traditional values. It is assumed that there will be a denial of traditional values.

The method of the study is to set free associations for completion by the surveyed persons. The stimulus is the words-categories of "hot" themes related to modern times. Associations aim to track both the specific attitude and the attitude-negative or positive-to the phenomenon concerned. The "liquefied reality," in which modern life flows, leads to the regulation of personality to a group to which it belongs, and the personality is formed around values invaded externally, and to a large extent they represent reflection from the inside to the projection and protection of one's own world. The target group is young people who should have an idea about themselves but in the context of the orientation towards building a stable value system-20 - 25 years.

The procedure is as follows:

- Instruction is given that a certain number of words will be dictated for which the persons surveyed should indicate the first two words/expressions with which they associate them. Individuals write on their own sheets, in their own right, in order to minimize the possibility of preliminary consideration.

- The following categories are listed: Gender, Violence, Social Networking, 
Tattoos, Vegan, Perfect Body, Addiction, Food, Love, Voting, Marriage, Freedom, Fashion, Beauty, Fear. They are dictated about 15 seconds to avoid thinking.

131 people were surveyed for the period from 1 to 15 April 2019. The sample consists 75 females (57.25\%) and 56 males (42.75\%) respondents. Females are predominant, which is explained by the fact that they are more social. By age category, the respondents are distributed as follows: 20 - 21 years in total 56 (42.75\%), where 32 are females (57.14\%) and 24 males (42.86\%); $22-23$ years in total $42(32.06 \%)$, where 18 are males (42.86\%) and 24 females (57.14\%); $24-25$ years in total $33(25.19 \%)$, where 12 are males (36.36\%) and 21 females (63.63\%). The choice of the categories of words is related both to topics that are up to date and relevant to modern times, and they are universal categories that strike the framework of individual functioning. It is predetermined both by the way it is integrated by the basic socialists and also by the transgenerational context. The choice of the target group, 20 to 25 year olds, aims to describe and understand the perception of young people about the reality and universal categories that in general can be metaphorically referred to as living regulators. The existing attitude is conducive to behavior.

The way of processing the data is as follows:

- The collected data on the stimulus material are categorized. Individual categories are used for each word. The aim is to cover diversity in relation to the perception of the persons surveyed.

- The categories are ranked, with emphasis on stimulus material, to which the associations create the largest network of categories, indicating broadness and is a predictor of a lack of common opinion or a conflict.

- The general categories of different stimulus material. If a similar category of association is seen in more than one word, this is considered indicative of the substantive impact of the respective stimulus on individuals.

- Words are gathered in general categories to monitor the attitude in its entirety.

- The most general attitudes about the categorization performed are ranked.

An analysis of both the number of categories determined and the content of the categories is analyzed, and then the substance of the words themselves falling into the categories is analyzed.

In the words Violence and Fear there is the widest distraction of the concept in terms of categorizing the associations. 7 categories have been found, and they have been dealt with separately and in their entirety. The broad range of associations in relation to the categories in which they can be placed are indicative of the form of uncertainty in which the concepts themselves fall. Logically, the greatest number of associations associated with the same Table 1 is derived from the abstractness of the concepts and their subjectivism.

In terms of violence and content, associations are ranked as follows: the largest number of definitions-52-relate to associations describing different forms 
Table 1. Categories related with violence and fear.

\begin{tabular}{cccc}
\hline & Violence & & Fear \\
\hline Descriptive, direct, rational & 52 & Direct (rational) & 48 \\
Emotional state & 37 & Emotional & 41 \\
Qualification action & 20 & Phenomena & 22 \\
Related to the victim & 11 & Fear, personal/psychic & 17 \\
Related to personality of the abuser & 10 & Fear animals/insects & 13 \\
Other & 6 & Fear of loss & 12 \\
The reason & 4 & Fear of pain & 7 \\
\hline
\end{tabular}

of violence-physical, verbal, combat, harassment, sexual, domestic (7) etc. state or emotion is a group of 37 responses that describe associations associated with the state or emotion associated with violence anger (6), fear (6), malice (5), pain (10); qualification of action 20 (violation, injustice...); associations related to the victim 11-woman, child, animal; associations related to the perpetrator's personality 10 soldier, man, complex...; associations related to the cause (4) alcohol, complex; another six ax, the other.

Concerning the contents of the associations to fear: The forms of rationalization 48 (irrational, dead-end, possession, problem, chains, hole, irrationality) prevail. Associations that fear the emotional experience 41 (horror, phobia, sadness, anxiety, insecurity, uncertainty)... Specific fears have been pointed out by the other subjects, they are categorized as types of fears because they are important in relation to common fears. 22 (high, sea, darkness, darkness) are most mentioned, followed by personal/mental stress 17 (separation, abandonment, loneliness, delusion), fears of animals/insects 14, fear of loss 12, loss) as well as fear of physical injury 7 (beating, pain, violence).

In both categories, the forms of rationalization and explanation of the concept fall to the greatest extent. This is indicative of the misunderstanding of the same and its placement in a space of consciousness, in which understanding, reasoning and consciousness are in a wide distance from the experience itself. Next is the positioning of emotional experiences that are related to violence and fear. The general plan follows the qualification of the act and the description of fear in its form of different phenomena. Only then are the categories related to the experience of the respective categories that are related to the interaction of objective reality with the subject or interpersonal interactions reasons for reaching violence and fear as a consequence. If a categorical conclusion is made, it should be focused on the limited personal experience of respondents to relevant phenomena. However, an attempt is made to give an assessment and an explanatory model that rationalizes or at least attempts to control reality. Risk awareness is not indicated, but rather superficial-descriptive. The many categories that relate to the concepts are indicative of general uncertainty among the surveyed people, which is probably and largely a consequence of the messages about socialization.

The content description confirms the above. It may be supplemented by the conclusion that the persons surveyed do not approve acts of violence, they are 
directed to a great extent to gender-based violence, and a male is perceived as a violent person. There is an awareness of people with the types of violence that is wide-ranging. In this sense, as a category of violence, it can be seen not as a rigid concept that comes in the context of a small number of varieties, but as a broad concept, covered by a large number of phenomena that are related to interpersonal relationships, particularly in the family. In connection with the etiology of violence as a phenomenon, the respondents point to a male person who abuses alcohol and has a low self-esteem. Given the assumption that there is no clear distinction in relation to the survival of violence, respondents describe more a priori, rationalizing, and may be assumed to represent the form of social representation of violence in the media, schools, social media and so on. It is positive that violence is not mentioned as a copying strategy on the part of the investigated persons, which confirms the existence of a negative assessment of the phenomenon.

The analysis of fear in content relation leads to the respondents' attempts at rationalization, which is rather a quest for avoidance, the denial of fear as a phenomenon. Rather, people surveyed are trying to present it as a constraint. There is no context in which fear is a constructive emotion associated with the regulation of behavior in an unfamiliar situation. Emotion that helps the individual to cope with a certain situation, perceiving it critically and rationally. There are three associations of fear with anxiety, which puts an interesting touch on the lack of restriction on the two concepts. There is also a transfer to the unpleasant experience, the polar horror, the panic that highlights the negative assessment of fear. Few aspects have been highlighted, such as uncertainty, truth, and placement in the context of the challenge, such as stumbling, impediment, urge, health. As a whole, fear is represented by its forms, as the categories of fear of loss and the personal categories associated with their own experiences are 29, and they are primarily directed towards loss, loneliness, and more and more clearly presented as contemporary problems in the interaction of personality. It is a good impression that only 7 words are referred to as fear of health, which may lead to the conclusion that young people have a higher emphasis on personality than on body health, which is indicative of lower anxiety in terms of activity. The high values of associations associated with objective phenomena nevertheless lead to conclusions related to insufficient survival experience with the objective, such as heights and darkness.

The next Word is freedom. Associated associations are summarized in 6 categories. Categories are again relatively many, which also has a connection with the universality of freedom itself as a category. These are presented in Table 2.

Content: Associations associated with state 54-happiness, freedom, life...; Associations related to objects 29 bird, flight, lover; Negative 22 prison, death, responsibility; Travel-8; Direct 6-the spirit...; Figures and others 4-Levski, Botev.

Describing freedom as a state brings the positive nuance of the purpose and 
Table 2. Categories related with freedom.

\begin{tabular}{cc}
\hline & Freedom \\
\hline Description of state & 54 \\
Direct associations/objectivization & 29 \\
Negative & 22 \\
Travelling & 8 \\
Direct (rationalization) & 6 \\
Figurative & 4 \\
\hline
\end{tabular}

direction of personal development, self-affirmation, and emphasizing the skill of mentalisation of reality in a way that puts the subject in the context of his own freedom. In this sense, freedom is idealized and not associated directly in the context of the state of the body, but rather of the mind. As an antipode, as if the representation of the collision between the leading association and the organized is objectively the second category, which includes descriptive categories. In this sense, the "Impossible or Unknown Freedom" approach, both conceptual and meaningful, appears. These associations are not personally focused on individuals but rather on the outside. Descriptively, the predominant bird and space speaks of an association of freedom with the absence of any boundaries, which is logical in view of the possibilities of personality, mind, mind, but not objectively through the "human" but through the bird and the expanse. This reflects the impossibility of experiencing the ideal that is the pursuit of the first category. From which it probably follows logically the third category of negative associations, which is a natural consequence of the clash between the expected state and the actual impossibility. The third negative category is conceivable, derived from the conflict between the first two. In the context of the smallest number of rationalizations available, the direct and the category of others, it is concluded that freedom in some sense goes through the pursuit without emphasizing the resistance or emphasizing the socially presented.

The next group of words in relation to the number of categories, the "movement" to them is one category less -5 categories, and that is why the increasing familiarity of the respective ones is conceivable. Words are gender, voting, beauty, tattoos, food. The categories are presented in Table 3.

Associations to Gender: directly used gender, social gender, third gender: 40; Negative definitions 34 numbers (foolishness, unfocused personality, excessive tolerance, confusion (here the dispersion is very strong), direct (biological) used words human, man, woman: 30, direct (discrediting) used words: gay, pederasty, (social) words used: discrimination, choice of difference, tolerance of 9, direct (administrative) used words: Istanbul Convention: 3 . There are also 82 positive attitudes and 62 negative in the respective category.

It is quite logical to conceive of this ideology, associations are extremely chaotic, and each category can be defined and determined by several subcategories 
Table 3. Categories gender, beauty, voting, tattoos, food.

\begin{tabular}{|c|c|c|c|}
\hline & Gender & & Voting \\
\hline Direct negative words (explanations) & 40 & Direct associations & 49 \\
\hline Direct biological & 30 & Negative & 47 \\
\hline Direct discrediting & 28 & Positive & 29 \\
\hline Direct social & 9 & Other & 9 \\
\hline \multirow[t]{2}{*}{ Direct administrative } & 3 & Direct & 6 \\
\hline & Beauty & & Tattoos \\
\hline Aesthetic & 51 & Positive value & 53 \\
\hline Direct (rational) & 39 & Negative value & 30 \\
\hline External & 32 & Direct (descriptive) & 27 \\
\hline Internal & 21 & Direct (figurative, rational) & 12 \\
\hline Vanity & 19 & Dangerous & 4 \\
\hline \multicolumn{4}{|c|}{ Food } \\
\hline Relation food-life & 57 & & \\
\hline Kind of foods - rationalization & 40 & & \\
\hline Necessity/Survival & 27 & & \\
\hline Quality of food & 23 & & \\
\hline Physical condition & 6 & & \\
\hline
\end{tabular}

that clearly reflect the negative or positive attitude of the persons surveyed to the respective phenomenon. Gender is the most associated with a form of social dysfunction and relevance to biological gender, which subsequently changes. If it is to be defined in the context of the other words, the personal attitude here is extremely emphasized, the underlined descriptive model is lacking, which puts the individual apart in his mental field. Rather, it is perceived as something up to date, something familiar, to which a negative attitude is maintained, which is largely irreversible at present. Only 9 are the words in which there is a nuance of understanding and the likelihood of accepting the same. At the same time, there is no direction of the qualitative definition of the concept of gender. This makes conjecture and unfamiliarity, but the available emotional touch that is a consequence of socializing factors.

In connection with the Voting: Most direct associations are-49: Election 29, vote, voting 8, MEPs, Politics, President; There are 47 negative associationscorruption, falsehood, false promises, illiteracy...; 29 positive-democracy, freedom, expression of opinion; 6 direct associations are Boyko ${ }^{1}$ and GERB ${ }^{2}$; Others-9.

The most objectionable and negative associations are observed. Only 29 are the positive associations that link voting to the possibility of change, with the in${ }^{1}$ Prime minister of Republic of Bulgaria.

${ }^{2}$ Political party in Republic of Bulgaria 
dividual's own involvement by confiding their trust in someone who runs them. The high number of negative associations in the vote, apart from determining the negative attitude towards the process itself, also represents a connection with freedom as a concept. As defined above with 22 negative associations that are related to the missing subjective sense of freedom. Both can get the following explanatory pattern-there is a definite negative attitude towards freedom that is placed in the context of the same attitude towards those to whom it should be entrusted to manage. Hence, considered in their entirety, it can be argued that the essential as a problem of idealized freedom are the specific boundaries in the conditions of the leading socialist and not the existence of borders in general. Perhaps it is a sense of limitation in the context of our own country.

In summary, the associative network in which the vote is placed is the objective, observable, behavioral. It is weakly associated with the individual's will and participation of the individual in the context of choice.

In relation to beauty: The resulting associations are divided into 5 categories: Aesthetic categories (aesthetics, ideal, nature, flower, picture, landscape...) 51, follows Rationalization (obsession, relativity, subjectivity, the external beauty (appearance, woman, face, blue eyes, blonde hair...) 32, follows Directed to inner beauty (love, mom, attraction, personality, tenderness...) well-kept man, me...) 19.

Beauty is most associated with aesthetic, ideal, perfect. It is placed in the context of direct descriptions such as flower, picture, landscape. Despite the predominant association of aesthetically, combined with inner beauty (72), there is also a disturbing element that combines the rationalizations of beauty with its external expression and vanity (90). The problem that the investigators explain explains beauty is that they do not emphasize that it is a form of experience. It is, of course, perceived that more than one category escapes from "living", "experiencing", but rather seeks and uses some explanatory model, which can also be seen as a distance from the category. In its versatility, the beauty that is associated with the aesthetic and the experience of it is shifted outward. Objecting it as an attitude and placement of the center in the context of what is attainable puts one more stroke on the modern time, and the postmodern man, the fragmented person with a lack of integrity, but deformed and decomposed into separate elements that do not summarize, place the beauty in certain situational contexts.

In connection with Tattoos: there is a positive and negative assessment, as well as direct associations. Positive evaluation-53-individuality, self-expression, art, beautiful; negative assessment-30-addiction, disfigurement, restriction, prisoner...; direct associations-27-sleeve, heart, ink, needle skin...; risks-4 (AIDS).

Consequently, perhaps the shifting of beauty to external and observable gives as a consequence the consideration of tattoos in the context of the communicative means, which puts the logical conclusion for the positive evaluation of the same, which is also adequately described in the category of direct associations. 
Negative assessments, as well as the associated risks, are 34 in total, outlining the fraudulent and invalid framework, followed by a form of stigmatization of the individual. There is conventionality with tattoos, as there are similarities in perception, and the difference lies mainly in the positive and negative evaluation. In other words, people surveyed are aware of the substance, content of tattoos.

In relation to food: the largest number- 57 of the associations are related to the relation between food and life and the relationship with others; happiness (6), pleasure 11, satisfaction 2, life 11, energy, sense, art. 3 times the word love, which combined with warmth, parents, rest, tranquility describes the meaning of food and its perception as a communicative expression; types of food 40-predominantly dune, pizza, panic, burger but very often also salad; 27 of the associations are for necessity, need for survival; 23 associations relate to the qualities of food, warm, tasty; condition-hunger, eating 6.

The content of food to life is logical, considered in the context of maintaining an objective life. Situated in the context of living as well as in the pre-examined categories, the food supports the objectification, outlining, rationalizing of the different phenomena. Explained by this is the alienation of the individual by himself, of his contact with himself. The use of food as a communicative element, which is largely connected with the maintenance of the external one and the induction of inner comfort in one way or another, is worrying. The function of food for living is defined in places and as a sense as an art that moves the subject away from the actual experience or shows the desire to connect its basic needs with the enjoyment of pleasure from which its quests and aspirations are conceivable. The association of love with love is also indicative of the aforementioned claims. On the other hand, the variety of food in its varieties is placed, as descriptive are the presence of salad and healthy eating as they are again directed to the outside, to the maintenance of beauty. On the other hand, the pleasure elements of unhealthy food are presented in conjunction with dune, pizza, and the quest for a quick, seamless key to attaining short-term pleasure, which in part displaces the center of experiencing meaning, pleasure, and art.

The next group of words is fashion, marriage, love, addiction, vegan, ideal body. As a group, they are united by the narrowing of the number of categories that lead to the conclusion of a more extreme, clearer attitude towards the respective words. Associations are all in four categories. These are presented in Table 4.

In terms of substance, the word Fashion gives double categorization, as there is the possibility of categorizing positive and negative assessments in the persons surveyed. The categories in which respondents refer to their associations are superficial categories (clothing, money, vision, product, red brandy...) 68. Following are the explanatory models (mania, constraint, obsolete...) 50 which carry with them the valuation the majority of the fashion is considered negative, as the distribution is the following: 20 are negative, and the positive ones are only 5 , the others being indifferent describing only what is fashion. There are social categories that include both personal qualities and social expression of fashion as 
Table 4. Categories fashion, marriage, love, addiction, vegan, ideal body.

\begin{tabular}{cccc}
\hline & Fashion & & Addiction \\
\hline Superficial categories & 68 & Forms (descriptive) & 110 \\
Direct (rational) & 50 & Evaluation & 23 \\
Social categories & 26 & Consequence & 19 \\
Aesthetic categories & 23 & Others & 2 \\
\hline & Marriage & & Vegan \\
\hline Positive & 52 & Negative & 52 \\
Direct & 42 & Foods & 42 \\
Negative & 34 & Positive & 33 \\
Others & 5 & Others & 14 \\
\hline Quality/Features/Descriptive & 80 & Descriptive models & 46 \\
Forms of love & 40 & Negative & 38 \\
Negative & 11 & Personal efforts & 36 \\
Figurative & 7 & Others & 17 \\
\hline & & & Ideal body \\
\hline & Love & & 46 \\
\hline
\end{tabular}

socially inclusive (socially desirable, individual, own style, determination...) 26, followed by aesthetic categories (beautiful, women, style...), which are only 23.

It is conceivable that the negative assessments of fashion predominate, and that there is actually no penetration into the essence of the concept, but rather an attempt to explain or put into its expressions the objective, touchable. Aesthetic and social categories are minimal at the expense of others, which does not put fashion as a criterion, something followed, but rather places the faces in opposition to fashion and modern. It would be interesting to establish the component of resistance to the respective concept and its reference to the context of the pursuit of a socially defined category, to add the element of comparison and the interaction with otherness. Rather, it focuses not on the communicative function of fashion but on its neurotic aspects, which are associated with illness, the "personal deficiency" of those who follow it. One of the probable reasons for this is precisely the alienation of one's own personality, which is visible from the categories above. The description, the understanding, but the meaningless content, the unrequited personality. Striving for a lost personality.

Deepening further into marriage and love, the associative networks associated with marriage are first introduced, the positive associations-50: love, cohabitation for life, happiness, harmony, unity...; Here are the direct associations-42: family, rings, rings, wedding, white, bride...; Negative associations are 34-overwhelming, fetters, prison; Five other associations fall into the category. As the overwhelming associations associate close marriage with love, the data are considered in their entirety, respectively the associative love network, which has the most quality associations-80, according to which love is happiness (11), shar- 
ing, warmth, caring for the other, understanding, the best thing in life, freedom, dedication...; 40 of the associations are the expressions of love-partner, family, sex, maternal love, love for people, nature, animals; negative associations are 11-unhappy love, deception, sacrifice; in the other category there are 7 associations-specific names, mom.

In content terms, the respondents are more categorical in the happiness that follows directly from love, and the marriage is presented as a positive continuation, which is institutionalized. Love is considered in its entirety, besides the emotional component that connects it positively with living, the social and objective component is represented, which recreates its manifestations and the experience of it. In this sense, love, along with freedom, can be credited as the words that awaken the emotional and social component of living. Idealized and to a lesser extent rejected. Completely filling the content of the quest for "being" in the context of individuality and the narrow social in the conditions of love. The institutionalization of marriage, on the other hand, is seen as a direct continuation of positive components as well as something negative, institutionalization, restriction of freedom, and so on. This makes the fundamental values of the young, which are aimed at the objective, and the spiritual and the inner reflected in freedom and love. The statement is meaningful, beyond the over 50 associations that positively appreciate marriage, as the associative network is followed by a symbolic one with gradation to the definition as a prison and an ominous. In the field of reasoning there is also the quest for the lack of frames related to freedom. The simulation leads to the conclusion of escape from the corresponding initiation, which is strongly associated with the objectification of marriage.

After marriage and love, the relevant group considers the word vegan, saturated with the nuances of modern social trends, which support the easier identification of the subject with a particular group. The associations that run to it have a very wide dispersion: negative ratings $52 \mathrm{crazy}$, herbivore, overdose, fancy, fashion, stupidity, inferiority; associations with food 42 green, vegetables, fruits, including meat...; positive ratings 33 choices, happy, love of animals, ecology...; others 14. The vast majority of associations are in the negative assessment as well as the food that is consumed. Along with the gender-related attitude of fashion, the word vegan gets a form of explanatory pattern. Predominantly negative is the attitude towards the appropriate incentives, which is also relevant to those who share the respective values. Perhaps this comes in the context of individualism and the quest for authenticity, which is also deduced from the motto phrases that include "Be yourself..." or the sequel with quality features that include "I am myself" and so on. The readiness to stigmatize membership of a group leads to a conclusion about the rigidity of the people surveyed in connection with modern trends, which may rather translate into a transgenerational conflict and socially inherited different values whose resonance is clearly expressed in the attitude towards marriage, the attitude to vote. However, there is a non-recognition of otherness, which is unknown, misunderstood. Respon- 
dents declare a desire for individuality and the right to choose others, but their attitudes towards certain forms of otherness are negative. As a reference point for the progress of their social comparisons are the contrasts that help them define themselves. In most cases, there is no deeper insight into the associative networks presented and the social component that presents itself as a rebellion to the comparison. The negative attitude towards fashion and the modern character of given phenomena are also a form of explanation that has its logic in the presented here. After a vegan, the ideal body, which is a new trend, the pursuit of which, together with a healthy lifestyle, are recognized as neurotic. Perfect body: direct associations, explanations 46 model, weak, muscular, beautiful, healthy, tattoos, athlete, perfect shapes...; negative illusion, no, mania, stereotype...; fruit of personal effort 36 fitness (14), training, sport, effort, choice; my other, my personalities. Although the trend is new, the quest is relatively modern, there are no predominantly negative assessments, and in particular skills for explaining the same, the personal will of the individual and others, which are related to evaluating themselves, as well as mentioning certain individuals, possibly with a function of comparisons. This brings on the one hand the attitude towards the ideal body and the objective, as external, as visible and measurable, not the deep and personal, which is associated with the attitude towards the beauty, which is exported outwardly. On the other hand, however, taken in the field of vegan, for example, a form of nutrition, living, philosophy, it is clear that the negative attitude is not to the outside, but to the person, to the respective group. In other words, some of the above categories are not referred to as a logical reason for achieving something else, which is a quest, such as a vegan to an ideal body, on the contrary. The problem is in the attitude towards the group, social. Moreover, taking into account the attitude towards food, which ultimately impresses with its strong social element, communication, attitude, etc. (see above).

Going to the next category of Addiction, it is remarkable that 110 of the associations are with the addictions: drug 48 , alcohol 19 , cigarettes 17 , $\operatorname{man} 8$, food 6 , social networks 3 , grass 3 , coffee 2 and 4 other gambling, financial, sport; follow the evaluative 23 weakness, disease; and those as consequence/result 19 lifestyle, obsession, addiction; others 2 .

In essence, the attitude towards addiction is evident through the familiarity with the same, the representation of the different species, and the forms of addictions. The social functions of addiction are very poorly affected, and we are judged by the evaluating associations about it in this respect. They portray it as a weakness, as a personal and social instability. Understanding addiction as a way of life is also a component that should be discussed in terms of the existence of this perception. The emerging question is the extent to which addiction on living can be related, and how much addiction relates to the end of life or death. There is only one association for "death", which is in the category of consequences/ result. This means that Addiction is not related to the respondents with the word fear, it is rather understood, but not a component that is understood but not 
evaluated as a risk. Perhaps the reason for this is that addiction is also strongly associated with the consumption of alcohol, cigarettes, coffee and so on. This places it in the context of a way of life. An interesting and relevant analysis of this is the lack of knowledge of social groups that use certain lifestyle habits and addiction is not so badly negative. It is as if it is accepted as a human being.

The last word that is being considered is social networks. It is represented in three categories in Table 5.

Social networks are represented with the largest number of direct associations-60-Facebook 32, Instagram 17 and Internet 11; the other associations polarize in a negative and positive assessment, such as a negative evaluation of 46 lost time, vanity, fake, depression and, above all, dependence, bondage, pressure; Positive rating 36 for friends, awareness, connection to the world and necessity.

It is obvious that the largest number of people surveyed associate social networks with Facebook, followed by an Instagram. The clarity of this also speaks of the understanding of the semantics of the word. A negative assessment gives reason to believe that there is a lack of response from respondents to using social networks as both a copy strategy and something useful. It is negative in the sense of the categories to which a negative attitude is presented above. This is worrying from the point of view of the conceivable limited representation and the limited work/encounter with the social network. From the positive ratings, the benefits are crystallized, but they seem to sink into the shadow of the negative and explanatory.

\section{Conclusion}

The study confirms the leading hypothesis, which is related to the objectification of the concepts. There is a greater knowledge of the representation of knowledge about it and the formation of a simple attitude towards approval or disapproval. Living on the other hand is intensely associated with nutrition, which is typical of the consumer, ultramodern society. In emotional terms, freedom and love, which are largely idealized in the context of "unachievable", are closest to young people. This is confirmed by the attitude towards fashion, which is predominantly negative. They also emphasize individualism, the pursuit of freedom of expression, as evidenced by the attitude towards tattoos, for example. The negative attitude towards marriage, its misunderstanding confirms the denial of traditional values. Thus, the conscious functioning of young people can be placed in the context of the rational, descriptive and formed positive or negative attitude towards contemporary social reformulation. Confirmation of the accepted

Table 5. Category social networks.

\begin{tabular}{cc}
\hline & Social networks \\
\hline Direct associations & 60 \\
Negative value & 46 \\
Positive value & 36 \\
\hline
\end{tabular}


hypotheses leads to challenges for future studies that are related to the evaluation of the Self in these contexts and the positioning of personality in linguistic constructs-short messages that are close to the personality of the respondents. The limitation of the research and the challenge for the future is the understanding of the content and the connection with the meaningful meaning of the defined categories. The author's interest is the deep understanding of the algorithm by which the perceptions of objective reality becomes a goal, way of life and a factor, which changes the social reality.

\section{Conflicts of Interest}

The author declares no conflicts of interest regarding the publication of this paper.

\section{References}

Bakracheva, M. (2009). Identichnostta v tri stapki [Identity in Three Steps]. Sofiya: Paradigma.

Gergen, K. (1991). The Saturated Self: Dilemmas of Identity in Contemporary Life. New York: Basic Books.

Gergen, K. (2000). The Self in the Age of Information. The Washington Quarterly, 23, 201-214. https://doi.org/10.1162/016366000560656

Gergen, K. (2012). From Reflecting to Making: Psychology in a World of Change. Europe's Journal of Psychology, 8, 511-514. https://doi.org/10.5964/ejop.v8i4.545

Laskoski, P. B., Gastaud, M. B., Goi, J. D., Bassols, A. S., Machado, D., da Costa, C. P. et al. (2013). Hypermodernity and the Psychoanalytic Clinic. Revista Brasileira de Psicoterapia, 15, 14-24.

Sapundzhieva, K. (2015). Fragmenti ot biografiyata na postmoderniya chovek [Fragments from the Postmodern Man Biography]. Drugite $v$ biografiyata na lichnostta (pp. 134-172). Sofiya: UI “Sv. Kliment Ohridski”.

Sapundzhieva, K. (2018). Pogled pred sebe si (hipermoderni fragmenti na otgovornostta) [A Look in Front of You (Hypermodern Fragments of Responsibility)]. Pogled pred sebe si-lichnata mrezha na obshtuvaneto (pp. 77-100). Sofiya: UI "Sv. Kliment Ohridski”.

Zimmel, G. (2014). Fragmentarniyat harakter na zhivota-Eseta [The Fragmented Character of Life-Essays]. Sofiya: Kritika i Humanizam. 